\title{
Therapeutic effect of ginsenoside Rg1 on mastitis experimentally induced by lipopolysaccharide in lactating goats
}

\author{
Y. M. Wang, Y. Q. Ma, S. C. Bi, X. D. Ma, R. Guan, S. H. Wang, M. Q. Lu, F. S. Shi, and S. H. Hu* \\ Department of Veterinary Medicine, College of Animal Sciences, Zhejiang University, Zhejiang 310058, China
}

\begin{abstract}
Escherichia coli is a cause of subclinical and clinical mastitis in dairy cattle and goats, and sometimes causes severe clinical disease that may result in death of the animal. Previous investigation showed that ginsenoside Rg1 extracted from Panax ginseng C.A. Meyer (Araliaceae) has an anti-inflammatory effect on the sepsis induced by E. coli lipopolysaccharide via competitive binding to toll-like receptor 4 . We hypothesized that intravenous injection of Rg1 had therapeutic effect on mastitis experimentally induced by intramammary infusion of lipopolysaccharide in lactating goats. In this study, 9 lactating goats were randomly assigned to 1 of the 3 groups: (1) lipopolysaccharide intramammary infusion + saline intravenous injection, (2) lipopolysaccharide intramammary infusion $+\mathrm{Rg} 1$ intravenous injection, and (3) saline intramammary administration + saline intravenous injection. Because no adverse clinical signs were observed after intramammary infusion of saline and intravenous injection of $\operatorname{Rg} 1$ in a preliminary experiment, and available qualified goats were limited in this study, this treatment was not included in this study. One udder half of each goat received intramammary infusion of lipopolysaccharide $(50 \mu \mathrm{g} / \mathrm{kg}$ of body weight; groups 1 and 2) or saline solution (group 3), and the other half was infused with $2 \mathrm{~mL}$ of saline solution at $\mathrm{h} 0$. Afterward, intravenous injections of saline solution (groups 1 and 3) or $\mathrm{Rg} 1(2.5 \mathrm{mg} / \mathrm{kg}$ of body weight; group 2) were administered at h 2 and 4 postlipopolysaccharide challenge. Blood and milk samples were collected $3,6,9,12,15,18,21,24,48$, and 72 $\mathrm{h}$ post-lipopolysaccharide challenge, and clinical signs were monitored hourly after lipopolysaccharide challenge within the first $10 \mathrm{~h}$ and at the same time points as blood samples. The results showed that Rg1 treatment downregulated rectal temperature, udder skin temperature, udder girth, milk somatic cell count, and
\end{abstract}

Received June 26, 2018.

Accepted November 13, 2018.

*Corresponding author: songhua@zju.edu.cn
N-acetyl- $\beta$-D-glucosaminidase and upregulated milk production, lactose, and recovered blood components, such as white blood cells, neutrophils, lymphocytes, total proteins, albumin, and globulin. Considering the positive therapeutic effect on lipopolysaccharideinduced mastitis in goats presented in this study as well as the anti-inflammatory activity found previously, the botanical Rg1 deserves further study as a therapeutic agent in the treatment of $E$. coli mastitis in dairy animals.

Key words: ginsenoside Rg1, lipopolysaccharide, mastitis, anti-inflammation

\section{INTRODUCTION}

Mastitis is an inflammation of the mammary gland frequently caused by IMI by pathogenic bacteria. Mastitis is one of the most important diseases of dairy animals, and the economic losses are huge due to reduced milk production, poor milk quality, early culling, cost of veterinary services, and the extra cost of management (Sharma, 2010). Most dairies rely on antibiotics to prevent new cases of mastitis during the cow's nonlactating period and to treat clinical cases of mastitis during lactation (Werner et al., 2010). Due to the growing public concern on antimicrobial-resistant pathogens in milk resulting from mastitis treatment, many researchers have become interested in phytotherapy for IMI. Although the use of medicinal herbs to treat human and animal diseases has a long history, and botanical products used in bovine mastitis treatment have been described in previous research ( $\mathrm{Li}$, 2011; Liu and $\mathrm{Xu}, 2014$ ), few randomly controlled trials have been reported. Francoz et al. (2017) recently reviewed nonconventional antimicrobials in the treatment of mastitis in dairy cows. After evaluating trials reporting specific data on clinical or bacteriological cure (or both), those authors found that no evidence-based recommendations can be given for the use of alternative or nonantimicrobial conventional treatment for clinical mastitis because of the low number of high-quality trials for each treatment. In their review, a series of clinical trials using botanical products were cited. In 


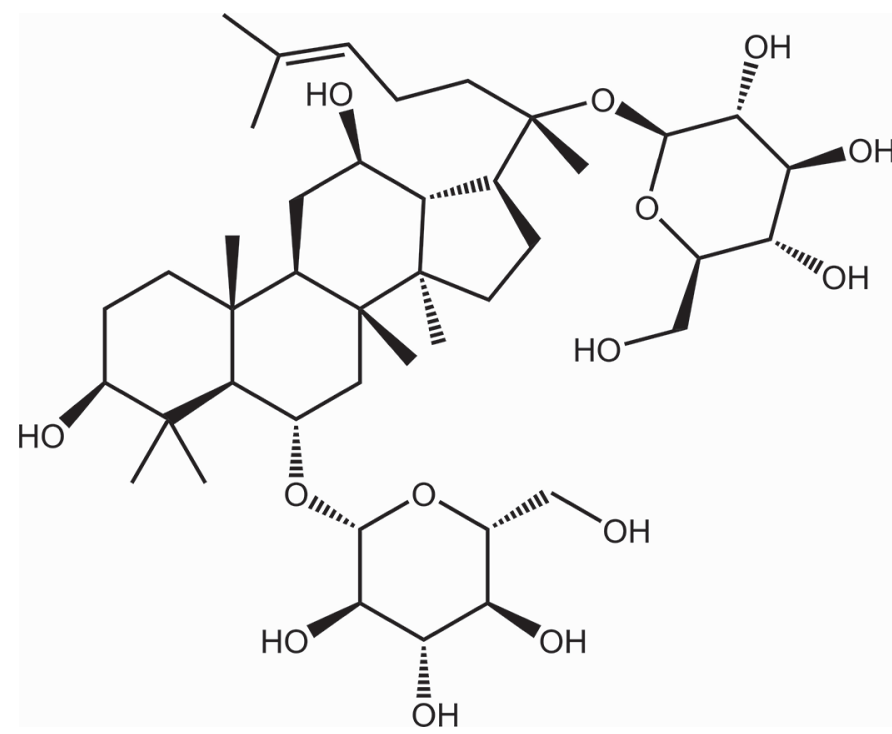

Figure 1. Chemical structure of ginsenoside $\mathrm{Rg} 1\left(\mathrm{C}_{42} \mathrm{H}_{72} \mathrm{O}_{14}\right.$; molecular weight, 801.024).

$\mathrm{Hu}$ and $\mathrm{Du}$ (1997), very similar and high cure rates were observed between conventional (antibiotics) and alternative treatments (houttuynin sodium bisulfate; 88 vs. 90\%). In the Pinedo et al. (2013) study, no differences in clinical or bacteriological cure rates were observed between cows treated with essential oils and a negative control group. Kai et al. (2003) observed differences in udder firmness and in gland swelling between glycyrrhizin-treated and antimicrobial-treated cows. Those authors found lower firmness score at $\mathrm{d} 2$ and 7 for glycyrrhizin-treated cows, but higher swelling score at d 1,2, and 7, and lower CNS count in milk of antimicrobial-treated cows at d 1, 2, and 7. Although many botanicals were reported to have a positive effect on mastitis treatment, the mechanisms for the therapeutic effect are still unclear and few have been accepted for practical use on dairy farms. Therefore, searching for effective botanical agents for mastitis treatment remains an interesting topic.

Escherichia coli, a gram-negative environmental pathogen, is a prominent cause of clinical mastitis in dairy cows and goats (Blum et al., 2014). Earlier studies have indicated that antibiotic therapy offers little or no efficacy in resolving mastitis caused by coliform pathogens (Erskine, 2000). In the case of E. coli mastitis, LPS released from the bacterial cell walls stimulates production of several proinflammatory cytokines via the toll-like receptor 4 (TLR4) signaling pathway, such as IL-1 $\beta$, IL-6, IL-8, and tumor necrosis factor alpha ( TNF- $\alpha$ ), that cause profound inflammation and tissue damage in the mammary gland (De Schepper et al., 2008). Clinical signs of mastitis include significant increase in local inflammatory mediators with a strong systemic acute phase response.

Ginsenoside Rg1 (Rg1) is an extract made from the root of Panax ginseng C.A. Meyer, which has been used as a traditional Chinese medicine for thousands of years (Bai et al., 2018; Li et al., 2018). The agent has been found to have anti-inflammatory effects. Injection of Rg1 into mice inhibited excessive expression of multiple proinflammatory mediators and successfully rescued the mice from LPS-induced death (Su et al., 2015a). The protective effect of $\operatorname{Rg} 1$ is suggested to result from its competitive binding with LPS to TLR4 and interrupting LPS-associated inflammation (Su et al., 2012, 2015a; Zhao et al., 2014). The objective of our study was to evaluate Rg1 for its therapeutic effect on mastitis experimentally induced by intramammary infusion of LPS in lactating goats. The mastitis described in this study also served as a model for cows.

\section{MATERIALS AND METHODS}

\section{Chemicals}

Ginsenoside Rg1 extracted from the root of P. ginseng was purchased from Chengdu Biopurify Phytochemicals Ltd. (Chengdu, China). The purity of Rg1 was $>99.7 \%$, as determined by HPLC; the chemical structure is shown in Figure 1. Lipopolysaccharide $(E$. coli O111:B4) was purchased from Sigma Chemical Co. (St. Louis, MO).

\section{Goat Mastitis Model}

We used 9 clinically healthy Saanen dairy goats (2223 mo old) with a BW at $49.8 \pm 1.8 \mathrm{~kg}$ and a daily milk yield of $1,192 \pm 28 \mathrm{~mL}$. The goats were in their first lactation with DIM ranging from 192 to 215 at the initiating of the study. All goats had milk SCC $<400,000$ cells/mL with negative bacteriological examination in the beginning of the study. The animals were randomly divided into 1 of the 3 groups: (1) LPS challenge [intramammary (IMM)] + saline intravenous injection (i.v.), (2) LPS challenge (IMM) + Rg1 (i.v.), and (3) saline administration (IMM) + saline (i.v.). One udder half in each goat received IMM infusion of LPS $(50 \mu \mathrm{g} / \mathrm{kg}$ of BW; groups 1 and 2) or saline solution (group 3), and the other half was infused with $2 \mathrm{~mL}$ of saline solution at time 0 . Before infusion, LPS was dissolved in saline solution at a concentration of $1.2 \mathrm{mg} / \mathrm{mL}$. The dose of LPS was chosen based on previous reports $(\mathrm{Pu}$ et al., 1998; Miao et al., 2007; Zhong et al., 2008), where goat mastitis was induced by IMM infusion of $50 \mu \mathrm{g} / \mathrm{kg}$ of BW of LPS. We also successfully induced mastitis by IMM infusion of the same dose of LPS $(50 \mu \mathrm{g} / \mathrm{kg}$ of 
BW) in a preliminary experimental goat. Two hours post-LPS challenge (PLC), 2 intravenous injections of saline solution (groups 1 and 3 ) or $\operatorname{Rg} 1(2.5 \mathrm{mg} / \mathrm{kg}$ of BW; group 2) were administered (jugular vein) with a 2 -h interval. The goats in groups 1 and 3 received saline solution (i.v.) equal to Rg1. Before treatment, Rg1 was dissolved in saline solution at a concentration of 12.5 $\mathrm{mg} / \mathrm{mL}$. The dose of Rg1 selected was based on previous observation, where intravenous injection of Rg1 at $12 \mathrm{mg} / \mathrm{kg}$ of BW was used to treat E. coli infection in rabbits (Su, 2015b). According to Yan (2001), $12 \mathrm{mg} /$ $\mathrm{kg}$ of BW in rabbits is converted into 1.9 to $2.5 \mathrm{mg} / \mathrm{kg}$ of BW in goats. The animal procedure was approved by the Institutional Animal Care and Use Committee at Zhejiang University and performed in accordance with the National Institutes of Health Guide for the Care and Use of Laboratory Animals.

\section{Measurement of the Udder Half Girth}

The measurement was performed from the anterior midline, through the posterior midline, and back to the anterior midline by passing the tape around the outside of udder through the inguinal region. To make certain each goat had the same size perimeter before IMM infusion of LPS, an udder half girth was drawn with a blue marker by the aid of a metal ring at a perimeter of 20 $\mathrm{cm}$, as shown in Figure 2. The girth was measured with a flexible ruler as indicated time points (Figure 3).

\section{Sample Collection and Analysis}

Before milk collection, the teat end and teat were scrubbed with a pad of absorbent cotton soaked in $70 \%$ alcohol and dried; the udder was massaged for approximately $15 \mathrm{~s}$ and the first 2 streams of milk from the teat were discarded. For bacteriological examination, 5 $\mathrm{mL}$ of udder half milk sample was aseptically collected in a plastic tube; for other analyses, udder half milk sample was collected into a sterile disposable plastic tube at $0,3,6,9,12,15,18,21,24,48$, and $72 \mathrm{~h} \mathrm{PLC}$. The volume of milk collected depended on the goat treated, ranging from 38 to $50 \mathrm{~mL}$.

For bacteriological examination, milk sample was incubated for 24 to $48 \mathrm{~h}$ at $37^{\circ} \mathrm{C}$ after being streaked on blood agar; the procedure was the same as described by Cao et al. (2007). No bacterial growth found on blood agar were considered bacteriologically negative. For other analyses, milk was preserved with bronopol (0.4 $\mathrm{mg} / \mathrm{mL}$ ) and kept at $4^{\circ} \mathrm{C}$ until use. Milk samples were analyzed for lactose (MilkoScan FT120, Foss, Hillerød, Denmark), milk SCC (Fossomatic Minor instrument, Foss), and $N$-acetyl- $\beta$-D-glucosaminidase (NAGase) activity (NAGase Detection Kit, Nanjing Jiancheng
Bioengineering Institute, Jiansu, China). Milk yield at the udder-half level was measured every $24 \mathrm{~h}$ from d -2 to 4 PLC.

Blood samples were collected by jugular venipuncture at the same time points as milk sampling and analyzed by IDEXX ProCyte Dx Hematology Analyzer (Westbrook, ME) for white blood cells (WBC), neutrophils (NEU), and lymphocytes (LYM) and by Roche Cobas c311 Automatic Biochemistry Analyzer (Roche, Basel, Switzerland) for total proteins (TP), albumin (ALB), and globulin (GLOB). Rectal temperature was measured at 1, 2, 3, 4, 5, 6, 7, 8, 9, 10, 12, 15, 18, 21, 24, 48 , and $72 \mathrm{~h}$ PLC.

\section{Measurement of the Udder Skin Temperatures}

The udder skin temperature (UST) was measured using a hand-held portable infrared imaging camera Mission C600 (Mission Infrared Optoelectronic Technology Company, Hangzhou, China) at the same time points as rectal temperature. The camera operated within the 8 to $14 \mu \mathrm{m}$ spectral band at 307,200 pixel $(640 \times 480)$ resolution with a sensitivity of $0.05^{\circ} \mathrm{C}$. The camera was adjusted for the ambient temperature conditions of each scanning before each measurement to compensate the reflected temperature. The emissivity value was set to 0.98 , which is the value commonly used for measuring the skin temperature in dairy cow udders (Hovinen et al., 2008). The infrared thermography pictures of each udder were taken immediately before and after milking at a set distance $(\geq 0.3 \mathrm{~m})$, and analyzed by a special

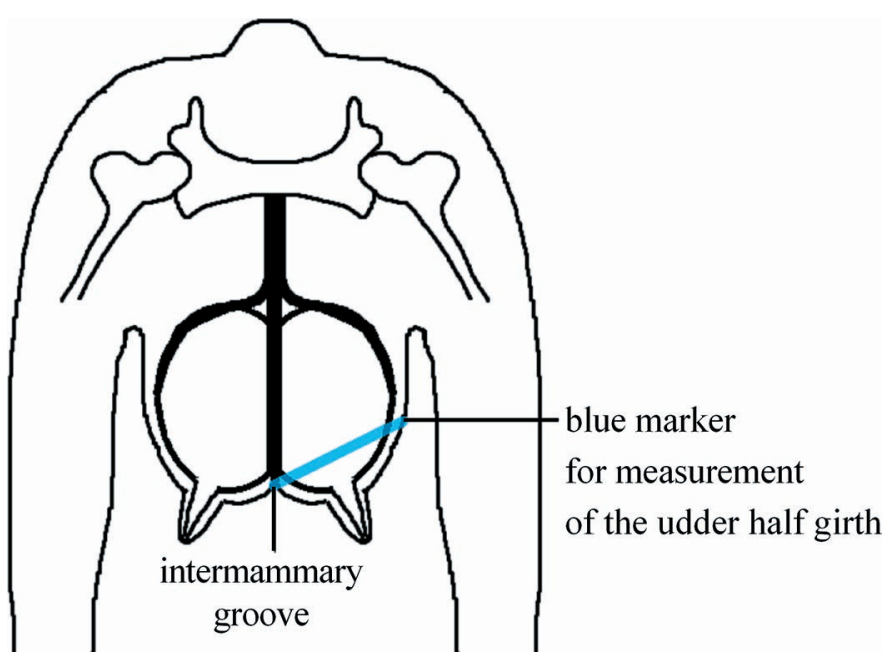

Figure 2. An udder half girth drawn with a blue marker by the aid of a metal ring with a perimeter of $20 \mathrm{~cm}$. Measurement was made from the anterior midline, through the posterior midline, and back to the anterior midline by passing a flexible ruler around the outside of udder through the inguinal region and expressed in centimeters. 

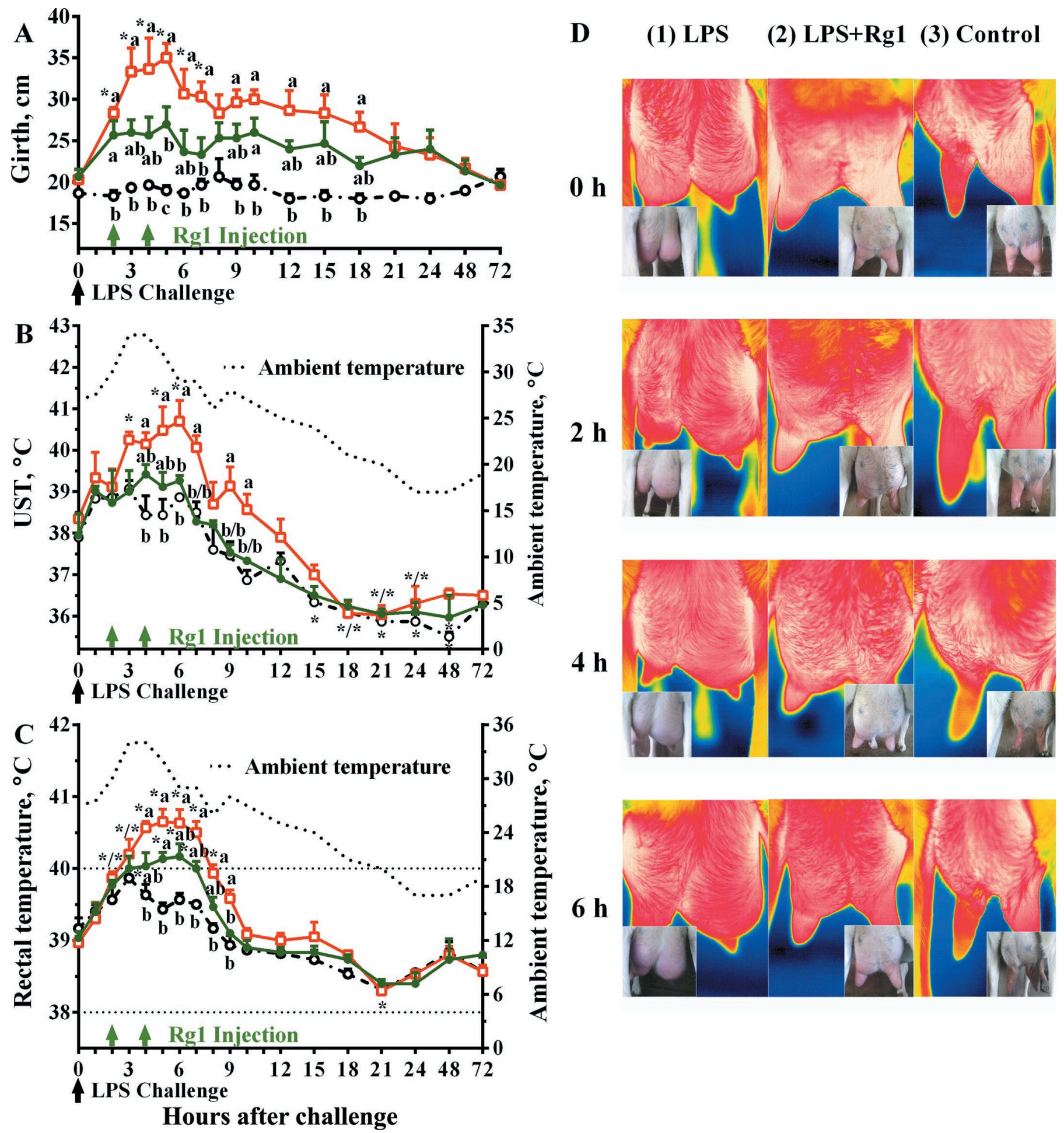

Figure 3. Effect of ginsenoside Rg1 on udder girth (A), skin temperature (UST; B), rectal temperature (C), and infrared thermographic images of the mammary gland (D) in goats with LPS-induced mastitis (3 goats/group). Only groups 1 and 2 were challenged with LPS, whereas group 3 was served as control. Means \pm SEM are used to express the data from groups $1(\square), 2(\bullet)$, and $3(\bigcirc)$. * indicates statistical difference $(P<0.05)$ compared with time 0 post-LPS challenge. Values with different letters $(\mathrm{a}, \mathrm{b})$ indicate statistical difference $(P<0.05)$ between groups at the same time point. 
thermograms analysis program developed by Mission Infrared Optoelectronic Technology Company.

\section{Statistical Analysis}

Data are presented as means \pm standard error of the mean. Rectal temperatures, blood parameters (WBC, NEU, LYM, TP, ALB, and GLOB.), milk parameters (SCC, NAGase, and milk yield), and the values (udder girth and UST) measured at the same time point were compared among groups using ANOVA from the MIXED procedure of SAS (version 9.4, SAS Institute Inc., Cary, NC) with Tukey-Kramer adjustment. The researchers were blinded to the groups the participating goats belonged to during the treatments and sample collection. $P$-values less than 0.05 were considered statistically significant.

\section{RESULTS}

\section{Clinical Signs}

Systemic and local responses of the goats to IMM infusion of LPS were clearly detected, as indicated in Figure 3. Compared with the goats receiving IMM infusion of saline solution in group 3, goats in groups 1 and 2 receiving infusion of LPS had increased body temperature $(P=0.01,4 \mathrm{~h}$ PLC $)$, UST $(P=0.03,4$ $\mathrm{h}$ PLC), and udder girth $(P=0.00,2 \mathrm{~h}$ PLC). The mammary glands infused with LPS became swollen and hard; infrared thermographic images showed that the most enlarged halves were those challenged with LPS in group 1. Compared with group 1, goats receiving intravenous injection of Rg1 in group 2 had reduced body temperature $(P=0.04,9 \mathrm{~h}$ PLC $)$, UST $(P=0.03,6 \mathrm{~h}$ PLC), and udder girth $(P=0.03,5 \mathrm{~h}$ PLC). In addition, injection of Rg1 relieved LPS-induced swelling of the mammary gland (Figure 3).

\section{Changes in Milk}

Compared with the goats receiving IMM infusion of saline solution in group 3, goats administered infusion of LPS in group 1 had decreased milk yield $(P=0.01$, $48 \mathrm{~h}$ PLC) and lactose content $(P=0.01,3 \mathrm{~h}$ PLC $)$ as well as increased milk SCC $(P=0.04,3 \mathrm{~h}$ PLC $)$ and NAGase activity $(P=0.01,6$ h PLC; Figure 4). In addition, infusion of LPS changed milk color from white into yellow. After receiving intravenous injection of Rg1, goats in group 2 had higher milk production $(P=0.01,48 \mathrm{~h}$ PLC $)$ and lactose content $(P=0.02$, $21 \mathrm{~h} \mathrm{PLC})$ as well as lower milk SCC $(P=0.04,6 \mathrm{~h}$ PLC) and NAGase ( $P=0.01,9 \mathrm{~h}$ PLC) than the goats without Rg1 treatment in group 1 (Figure 4).

\section{Changes in Blood}

Compared with the goats receiving IMM infusion of saline solution in group 3, goats administered infusion of LPS in group 1 had decreased WBC, NEU, LYM $(P$ $=0.04,6 \mathrm{~h}$ PLC $), \mathrm{TP}(P=0.05,3 \mathrm{~h}$ PLC $), \operatorname{ALB}(P$ $=0.02,12 \mathrm{~h} \mathrm{PLC})$, and GLOB $(P=0.00,6 \mathrm{~h}$ PLC $)$ in blood (Figure 5). However, blood WBC $(P=0.03$, 6 h PLC $)$, NEU $(P=0.08,6$ h PLC $)$, LYM $(P=0.05$, $6 \mathrm{~h}$ PLC), TP $(P=0.01,6$ h PLC $)$, ALB $(P=0.05$, $9 \mathrm{~h} \mathrm{PLC})$, and GLOB $(P=0.00,6 \mathrm{~h}$ PLC) increased in goats of group 2 after intravenous injection of $\mathrm{Rg} 1$ when compared with the goats without Rg1 treatment in group 1 (Figure 5).

\section{DISCUSSION}

Escherichia coli is an important environmental pathogen in dairy cows and goats (Blum et al., 2014). In the case of E. coli mastitis, LPS released from the bacterial cell wall stimulates production of several proinflammatory cytokines via TLR4 signaling pathway and causes profound inflammation and tissue damage in the mammary gland (De Schepper et al., 2008). The important finding of our study was the discovery of the positive therapeutic effect of Rg1 on LPS-induced mastitis in goats. Intravenous injection of Rg1 significantly decreased the body temperature, UST, udder girth, SCC, and NAGase in lactating goats with mastitis induced with LPS when compared with mastitic goats without Rg1 treatment. The Rg1 was also observed to increase milk lactose level and prevent a decrease of milk yield in LPS-challenged goats.

Gram-negative bacteria are one of the major mastitis-causing pathogens in ruminants. Those that elude host defense mechanisms grow in the udder (Sordillo and Streicher, 2002). The bacteria release toxins and induce PMNL and epithelial cells to liberate chemoattractants, such as TNF- $\alpha$ and IL- 8 , which attract circulating PMNL to the infected mammary gland (Sordillo and Daley, 1995; Paape et al., 2003; Zhao and Lacasse, 2008). Lipopolysaccharide can raise the set point of the body temperature of the hypothalamus by acting as an exogenous pyrogen through cytokine production (McGavin and Zachary, 2007), resulting in the higher body temperature. Meanwhile, Hovinen et al. (2008) stressed that the vasoconstriction of the peripheral blood vessels was observed during many IMI episodes. Extensive damage to the blood-milk barrier will cause enhanced external swelling of the gland (Viguier et al., 2009), which may result from the increased permeability of the capillaries that lead to the leak of plasma into the interstitium, causing edema (McGavin and Zachary, 2007). 

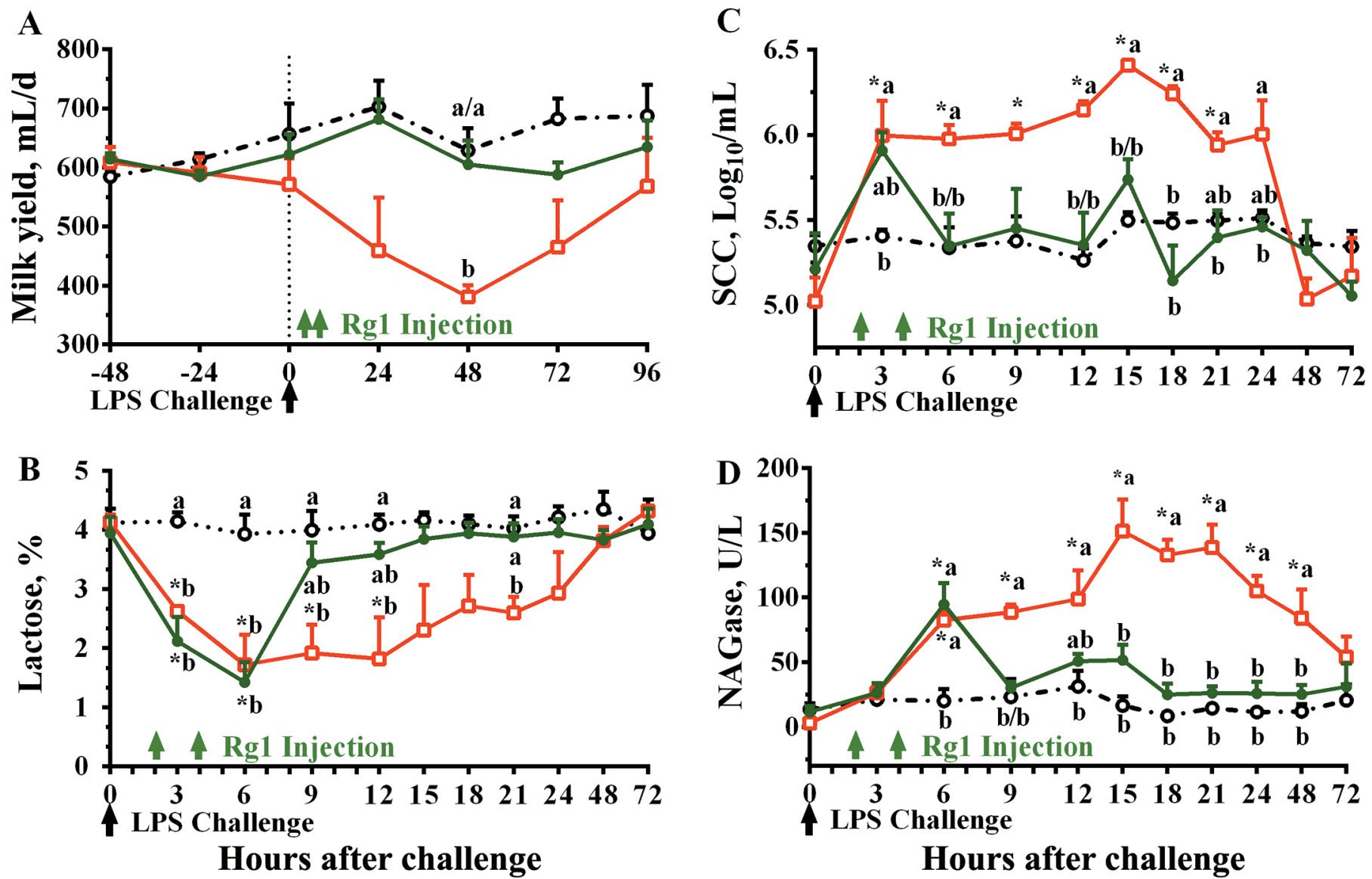

Figure 4. Effect of ginsenoside Rg1 on milk yield (A), lactose content (B), milk SCC (C), and $N$-acetyl- $\beta$-D-glucosaminidase (NAGase) activity (D) in experimental udder halves of goats with LPS-induced mastitis (3 goats/group). Only groups 1 and 2 were challenged with LPS, whereas group 3 was served as control. Means \pm SEM are used to express the data from groups $1(\square), 2(\bullet)$, and $3(\bigcirc)$. * indicates statistical difference $(P<0.05)$ compared with time 0 post-LPS challenge. Values with different letters $(\mathrm{a}, \mathrm{b})$ indicate statistical difference $(P<0.05)$ between groups at the same time point.

In our study, only the cell wall component LPS of the bacteria was used for IMM administration. Lipopolysaccharide is a strong stimulant of the inflammatory response but disappears with the first milking after IMM administration (Wall et al., 2018). Although our model stimulated inflammation very well, it has limitations representing real infection because bacteria would start to multiply once they invade the mammary gland in a natural case. In artificially induced experimental mastitis, various doses of LPS for IMM infusion have been used in the literature. Dhondt et al. (1977) IMM infused $3 \mathrm{mg}$ of LPS and induced mastitis in dairy cows and goats; Jarman and Caruolo (1984) infused $0.5 \mathrm{mg}$ of LPS into the mammary gland and induced mastitis in dairy goats; Wall et al. (2016) infused $0.2 \mu \mathrm{g}$ of LPS into the mammary gland and induced mastitis in dairy cows; Pu et al. (1998), Zhong et al. (2008), and Miao et al. (2007) used LPS at a dose of $50 \mu \mathrm{g} / \mathrm{kg}$ for IMM infusion and induced mastitis in dairy goats. Because the regions where Pu et al. (1998), Zhong et al. (2008), and Miao et al. (2007) carried out their experiments are closer to our regions, and these regions have similar feeding system and climatic environment, the same dose of LPS as in their experiments $(50 \mu \mathrm{g} / \mathrm{kg}$ of BW) was used in the current study.

Local and systemic responses to LPS-induced mastitis observed in our study (Figure 3) were similar to those observed in other studies (Lehtolainen et al., 2003; Hovinen et al., 2008; Giovannini et al., 2017). Our infrared imaging camera detected enlarged udder halves with elevated UST and rectal temperature, which paralleled the enlarged udder girths after the udder halves were infused with LPS (Figure 3); this indicated that acute mastitis was induced by IMM infusion of LPS in our study. Infrared thermography has also been found to detect the changes of UST in 
A

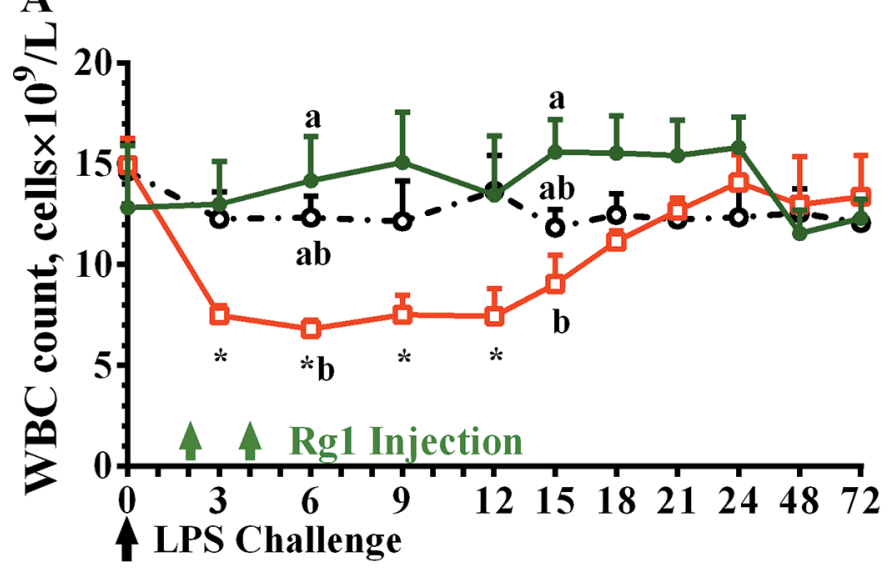

B

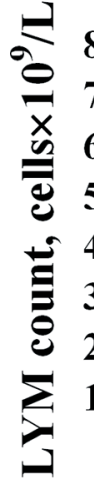

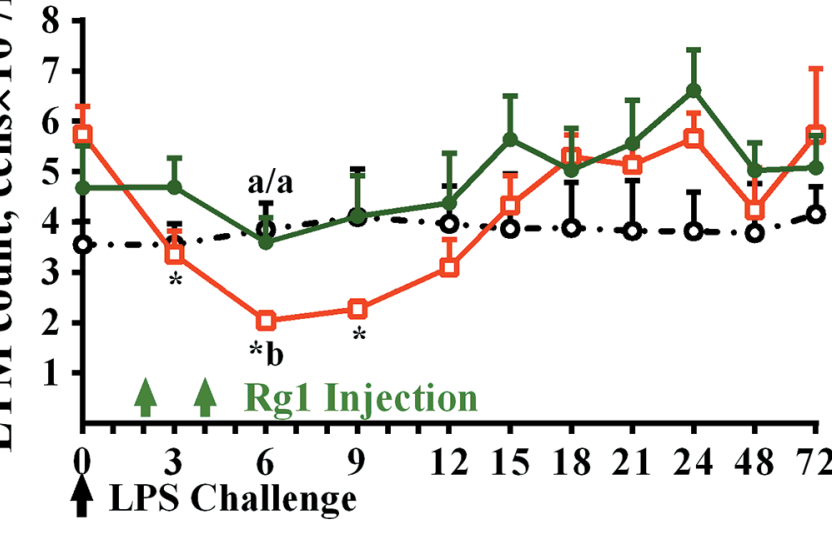

C

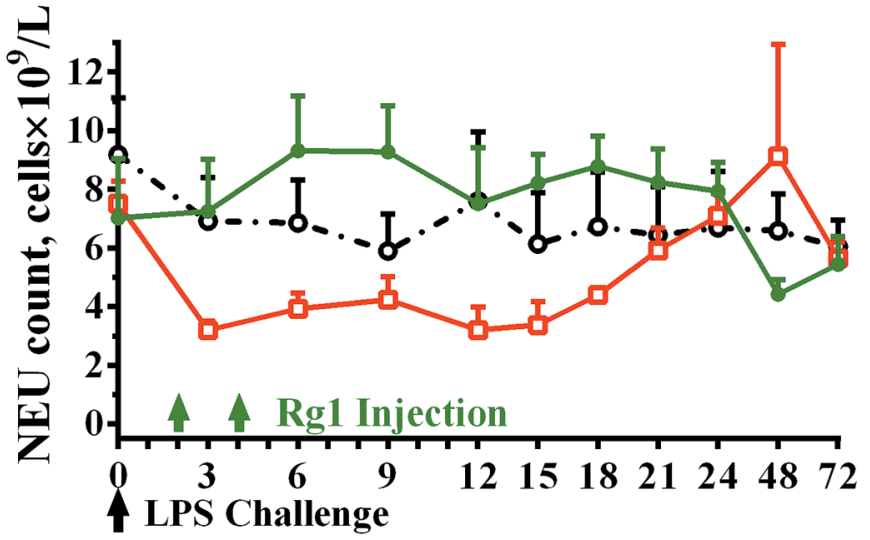

Hours after challenge
D

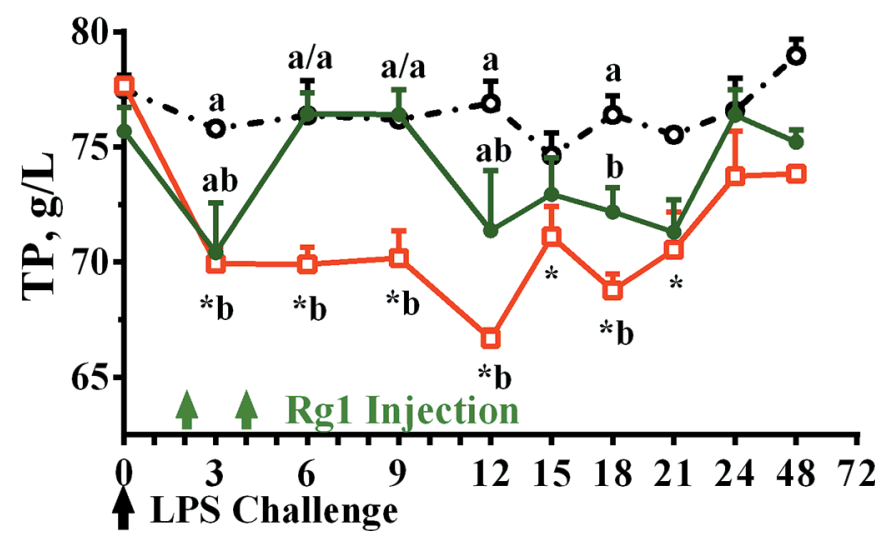

$\mathbf{E}$

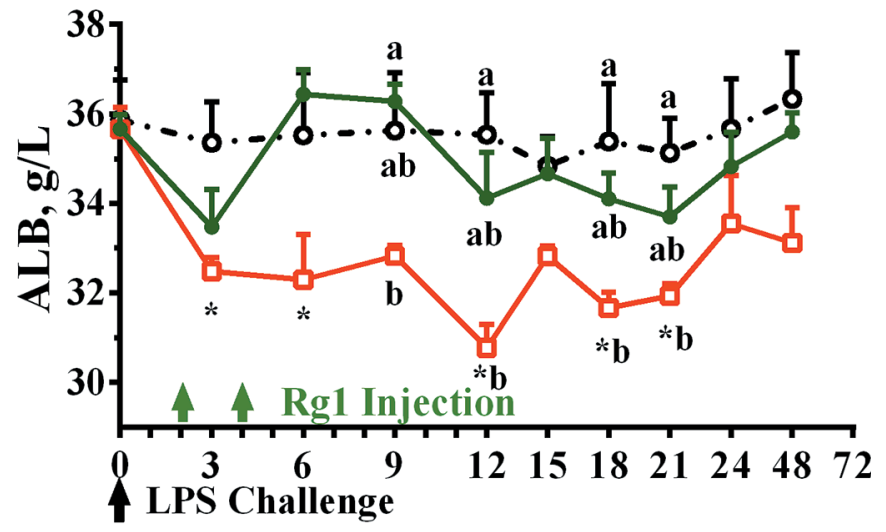

F

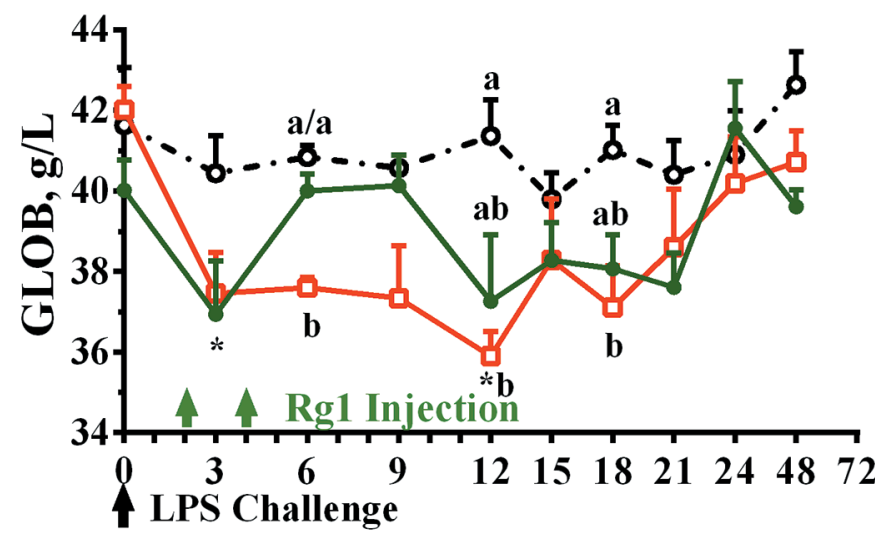

Hours after challenge

Figure 5. Effect of ginsenoside Rg1 on white blood cell (WBC; A), lymphocyte (LYM; B), neutrophil (NEU; C), total protein (TP; D), albumin (ALB; E), and globulin (GLOB; F) in lactating goats with LPS-induced mastitis (3 goats/group). Only groups 1 and 2 were challenged with LPS, whereas group 3 served as control. Means \pm SEM are used to express the data from groups $1(\square), 2(\bullet)$, and $3(\bigcirc)$. $*$ indicates statistical difference $(P<0.05)$ compared with time 0 post-LPS challenge. Values with different letters $($ a,b) indicate statistical difference $(P<$ $0.05)$ between groups at the same time point. 
other studies and significantly changed UST has been observed in clinical mastitis (Martins et al., 2013; Sinha et al., 2018; Zaninelli et al., 2018).

Decreased milk production and lactose in mastitic cases have been previously reported (Hoeben et al., 2000; Leitner et al., 2004; Martins et al., 2013). During IMI, blood PMNL are attracted into the infected sites, where they release extracellular reactive oxygen species, such as hydroxyl radicals (Boulanger et al., 2002), which are cytotoxic for mammary epithelial cells (Ledbetter et al., 2001; Lauzon et al., 2005). Microscopic examination indicated that epithelial cells could be damaged by treatment with intact, lysed, or phagocytosing PMNL (Capuco et al., 1986). The oxidants and proteases released by PMNL destroy the bacteria and some of the epithelial cells, causing a dramatic decrease of milk production and the release of enzymes, such as NAGase. Furthermore, high milk SCC are caused by leukocytes together with the sloughed-off mammary epithelial cells once their task is fulfilled (Paape et al., 2002, 2003). Similarly, decreased milk yield and lactose accompanied by increased milk SCC and NAGase were recorded in goats receiving IMM infusion of LPS in our study (Figure 4).

During mastitis, numerous PMNL and other cells pass through endothelium from blood into milk (Paape et al., 2003), which leads to the reduction of WBC in blood. Polymorphonuclear leukocytes and macrophages release enzymes, inflammatory mediators, and reactive oxygen species (ROS), by which they promote elimination of bacteria but also cause damages of surrounding tissues (Pham, 2006; Ryman et al., 2015) and dilate blood vessels with enhanced permeability of the blood-milk barrier. Wellnitz et al. (2016) found that pathogens such as E. coli had a great effect on the blood-milk barrier and a large amount of blood proteins were transferred into milk. Serum albumin has been suggested as a marker for infection and for estimating transfer of proteins implicated in the udder defense (Tothova et al., 2014; Wall et al., 2015; Sadek et al., 2017). Decreased blood WBC, NEU, LYM, TP, ALB, and GLOB observed in our study (Figure 5) may be attributed to the increased permeability of the bloodmilk barrier in the udder of goats challenged with LPS. Decreased blood cells accompanied by increased milk SCC in artificially induced mastitis have been observed in another study (Bannerman et al., 2004).

The positive therapeutic effect of Rg1 on LPS-induced mastitis found in our study may be attributed its antiinflammatory properties. Toll-like receptor 4 and its coreceptor, myeloid differentiation factor 2 (MD-2), form a heterodimer in host to recognize LPS. The interaction between LPS and TLR4-MD-2 activates the LPS signaling pathway, resulting in phosphorylation of nuclear factor $\kappa \mathrm{B}$ (Farrow and Evers, 2002); activation of nuclear factor $\kappa \mathrm{B}$ induces high levels of proinflammatory cytokines, enzymes, and other mediators, including TNF- $\alpha$, IL-1 $\beta$, IL-6, inducible nitric oxide synthase, and cyclooxygenase-2 (Surh et al., 2001). Consequently, strategies that include prevention of ligand binding to TLR4 (Hawkins et al., 2004) and blocking the interactions of TLR4 and adaptors in signaling pathways (Takashima et al., 2009) have been reported to be effective in intervening in the development of inflammation. Su et al. (2015a) observed that Rg1 competes with LPS to bind TLR4 in the cell membranes and diminishes LPS-induced proinflammatory mediators. We supposed that intravenous injection of Rg1 interfered with LPS to bind to TLR4 and suppressed release of proinflammatory mediators, decreasing both systemic and local inflammatory responses. Reduced mastitis resulted in less UST and udder swelling (Figure 3). Less damaged epithelium led to relatively greater milk yield with higher lactose as well as less milk SCC and NAGase (Figure 4). Decreased permeability of blood-milk barrier inhibited flow of blood components such as WBC, NEU, LYM, TP, ALB , and GLOB into milk (Figure 5 ). As only the cell wall component LPS of E. coli was used to induce mastitis in the present study, and this inflammation has limitations representing real infection because bacteria would start to multiply once they invade the mammary gland in a natural case, a further step would be to investigate the effect of $\operatorname{Rg} 1$ on $E$. coli-induced mastitis. To improve therapeutic efficacy, combination of Rg1 with other drugs might be necessary, such as botanicals, nonsteroidal anti-inflammatory drugs, oxytocin, and so on.

\section{CONCLUSIONS}

Lipopolysaccharide is an essential component embedded in the cell wall of $E$. coli. Once the bacteria invade the mammary gland, they multiply and release LPS after death to cause inflammation in the host. We successfully induced mastitis by IMM infusion of LPS in lactating goats. The present study is the first to demonstrate intravenous injection of Rg1 to successfully treat LPS-induced goat mastitis. Considering the positive therapeutic effect on mastitis shown in our study, as well as the anti-inflammatory properties found previously, further study should focus on the investigation of Rg1 for its therapeutic effect on mastitis caused by $E$. coli in dairy animals.

\section{ACKNOWLEDGMENTS}

This study was supported by the National Key R\&D Program of China (Project No. 2017YFD0502200; Bei- 
jing) and the National Natural Scientific Foundation of China (31372471; Beijing). We thank Hongchun Yang, Miaoqin Zhang, and Yimin Wang (Caiyang Animal Husbandry Co. Ltd., Hangzhou, China) technical assistance in sample collection, Changqing Ji, Chen Xing, Chengxing Liu, and Daxi Ren (Zhejiang University, Hangzhou, China) for assistance in milk and blood component detection, Hangzhou Mission Infrared Optoelectronic Technology Co. Ltd. (Hangzhou, China) for UST detection, and Wei Xu (Zhejiang University, Hangzhou, China) for valuable discussion.

\section{REFERENCES}

Bai, L., J. Gao, F. Wei, J. Zhao, D. Wang, and J. Wei. 2018. Therapeutic potential of ginsenosides as an adjuvant treatment for diabetes. Front. Pharmacol. 9:423.

Bannerman, D. D., M. J. Paape, J. P. Goff, K. Kimura, J. D. Lippolis, and J. C. Hope. 2004. Innate immune response to intramammary infection with Serratia marcescens and Streptococcus uberis. Vet. Res. 35:681-700.

Blum, S. E., E. Heller, and G. Leitner. 2014. Long term effects of Escherichia coli mastitis. Vet. J. 201:72-77.

Boulanger, V., X. Zhao, and P. Lacasse. 2002. Protective effect of melatonin and catalase in bovine neutrophil-induced model of mammary cell damage. J. Dairy Sci. 85:562-569.

Cao, L. T., J. Q. Wu, F. Xie, S. H. Hu, and Y. Mo. 2007. Efficacy of nisin in treatment of clinical mastitis in lactating dairy cows. J. Dairy Sci. 90:3980.

Capuco, A. V., M. Paape, and S. Nickerson. 1986. In vitro study of polymorphonuclear leukocyte damage to mammary tissues of lactating cows. Am. J. Vet. Res. 47:663-668.

De Schepper, S., A. Ketelaere, D. Bannerman, M. Paape, L. Peelman, and C. Burvenich. 2008. The toll-like receptor-4 (TLR-4) pathway and its possible role in the pathogenesis of Escherichia coli mastitis in dairy cattle. Vet. Res. 39:5.

Dhondt, G., C. Burvenich, and G. Peeters. 1977. Mammary blood flow during experimental Escherichia coli endotoxin induced mastitis in goats and cows. J. Dairy Res. 44:433.

Erskine, R. 2000. Antimicrobial drug use in bovine mastitis. Pages 712-734 in Antimicrobial Therapy in Veterinary Medicine, 3rd ed. J. Prescott, J. Baggot and R. Walker, ed. Blackwell Publishing, Ames IA.

Farrow, B., and B. M. Evers. 2002. Inflammation and the development of pancreatic cancer. Surg. Oncol. 10:153-169.

Francoz, D., V. Wellemans, J. P. Dupré, J. P. Roy, F. Labelle, P. Lacasse, and S. Dufour. 2017. Invited review: A systematic review and qualitative analysis of treatments other than conventional antimicrobials for clinical mastitis in dairy cows. J. Dairy Sci. 100:7751-7770.

Giovannini, A. E., S. Wall, O. Wellnitz, R. Bruckmaier, and C. Spadavecchia. 2017. Experimentally induced subclinical mastitis: are lipopolysaccharide and lipoteichoic acid eliciting similar pain responses? Acta Vet. Scand. 59:40.

Hawkins, L. D., W. J. Christ, and D. P. Rossignol. 2004. Inhibition of endotoxin response by synthetic TLR4 antagonists. Curr. Top. Med. Chem. 4:1147-1171.

Hoeben, D., B. Burvenich, E. Trevisi, G. Bertoni, J. Hamann, R. Bruckmairer, and J. Blum. 2000. Role of endotoxin and TNF- $\alpha$ in the pathogenesis of experimentally induced coliform mastitis in periparturient cows. J. Dairy Res. 67:503-514.

Hovinen, M., J. Siivonen, S. Taponen, L. Hänninen, M. Pastell, A. Aisla, and S. Pyörälä. 2008. Detection of clinical mastitis with the help of a thermal camera. J. Dairy Sci. 91:4592-4598.

Hu, S. H., and A. F. Du. 1997. Treatment of bovine mastitis with houttuynin sodium bisulphate. Zentralbl. Veterinarmed. B 44:365-370.
Jarman, R. F., and E. V. Caruolo. 1984. Temperature and milk composition responses to infusion of $E$. coli LPS and $S$. aureus vaccines in the goat. Zentralbl. Veterinarmed. A 31:740-750.

Kai, K., K. Komine, K. Asai, T. Kuroishi, Y. Komine, T. Kozutsumi, M. Itagaki, M. Ohta, Y. Endo, and K. Kumagai. 2003. Anti-inflammatory effects of intramammary infusions of glycyrrhizin in lactating cows with mastitis caused by coagulase-negative Staphylococci. Am. J. Vet. Res. 64:1213-1220.

Lauzon, K., X. Zhao, A. Bouetard, L. Delbecchi, B. Paquette, and P. Lacasse. 2005. Antioxidants to prevent bovine neutrophilinduced mammary epithelial cell damage. J. Dairy Sci. 88:4295-4303.

Ledbetter, T. K., M. Paape, and L. Douglas. 2001. Cytotoxic effects of peroxynitrite, polymorphonuclear neutrophils, free radicalscavengers, inhibitors of myeloperoxidase, and inhibitors of nitric oxide synthaseon bovine mammary secretory epithelial cells. Am. J. Vet. Res. 62:286-293.

Lehtolainen, T., S. Suominen, T. Kutila, and S. Pyörälä. 2003. Effect of intramammary Escherichia coli endotoxin in early- vs. latelactating dairy cows. J. Dairy Sci. 86:2327-2333.

Leitner, G., M. Chaffer, A. Shamay, F. Shapiro, U. Merin, E. Ezra, A. Saran, and N. Silanikove. 2004. Changes in milk composition as affected by subclinical mastitis in sheep. J. Dairy Sci. 87:46-52.

Li, G. X. 2011. New Traditional Chinese Veterinary Medicine, 1st ed. Shandong Science and Techonology Press Co. Ltd., Shandong, China.

Li, L., C. Pan, L. Yan, Y. Cui, Y. Liu, H. Mu, K. He, B. Hu, X. Chang, K. Sun, J. Fan, L. Huang, and J. Han. 2018. Ginsenoside Rg1 ameliorates rat myocardial ischemia-reperfusion injury by modulating energy metabolism pathways. Front. Physiol. 9:78.

Liu, Z. J., and J. Q. Xu. 2014. Chinese Veterinary Medicine, 4th ed. China Agriculture Press Co. Ltd., Beijing, China.

Martins, R. F., P. Paim, A. Cardoso, B. Dallago, C. Melo, H. Louvandini, and C. McManus. 2013. Mastitis detection in sheep by infrared thermography. Res. Vet. Sci. 94:722-724.

McGavin, M., and J. Zachary. 2007. Pathologic Basis of Veterinary Disease, 4th ed. Mosby-Elsevier, St. Louis, MO.

Miao, J. F., H. T. Ma, S. X. Zou, and W. H. Chen. 2007. Effect of endotoxin on enzymes and cytokines in mammary tissue of goats relating with mastitis. J. Fujian Agric. Forestry Univ. 36:608-613.

Paape, M. J., D. Bannerman, X. Zhao, and J. Lee. 2003. The bovine neutrophil: Structure and function in blood and milk. Vet. Res. 34:597-627.

Paape, M., J. Mehrzad, X. Zhao, J. Detilleux, and C. Burvenich. 2002. Defense of the bovine mammary gland by polymorphonuclear neutrophil leukocytes. J. Mammary Gland Biol. Neoplasia 7:109-121.

Pham, C. T. 2006. Neutrophil serine proteases: Specific regulators of inflammation. Nat. Rev. Immunol. 6:541-550.

Pinedo, P., H. Karreman, H. Bothe, J. Velez, and C. Risco. 2013. Efficacy of a botanical preparation for the intramammary treatment of clinical mastitis on an organic dairy farm. Can. Vet. J. 54:479-484.

Pu, S. J., C. Y. Bai, H. M. He, and H. W. Liu. 1998. Experimental mastitis induced by Escherichia coli endotoxin in dairy goats. Jiangsu Agric. Res. 19:80-82.

Ryman, V. E., N. Packiriswamy, and L. Sordillo. 2015. Role of endothelial cells in bovine mammary gland health and disease. Anim. Health Res. Rev. 16:135.

Sadek, K., E. Saleh, and M. Ayoub. 2017. Selective, reliable blood and milk bio-markers for diagnosing clinical and subclinical bovine mastitis. Trop. Anim. Health Prod. 49:431.

Sharma, N. 2010. Economically important production diseases of dairy animals. Pages 47-65 in Farm Management and Diseases. SMVS Dairy Year Book, Ghaziabad, India.

Sinha, R., M., T. K. Bhakat, A. Mohanty, R. Ranjan, S. A. Kumar, A. Lone, A. R. Rahim, K. Paray, Khosla, and Z. Danish. 2018. Infrared thermography as non-invasive technique for early detection of mastitis in dairy animals -A review. Asian J. Dairy Food Res. 37:1-6.

Sordillo, L., and M. Daley. 1995. Role of cytokines in the prevention and treatment of bovine mastitis. Pages 389-419 in Cytokines in 
Animal Health and Disease. M. J. Myers and M. P. Murtaugh, ed. Marcel Dekker Inc., New York, NY.

Sordillo, L. M., and K. Streicher. 2002. Mammary gland immunity and mastitis susceptibility. J. Mammary Gland Biol. Neoplasia $7: 135-146$.

Su, F. 2015b. Ginsenoside Rg1 and Re modulate immune responses and protect against endotoxin via TLR4 signaling pathway. PhD Thesis. Department of Veterinary Medicine, College of Animal Sciences, Zhejiang Univ., Hangzhou, China.

Su, F., Y. Xue, Y. Wang, L. Zhang, W. Chen, and S. Hu. 2015a. Protective effect of ginsenosides Rg1 and Re on lipopolysaccharide-induced sepsis by competitive binding to toll-like receptor 4 . Antimicrob. Agents. Chemother. 59:5654-5663.

Su, F., L. Yuan, L. Zhang, and S. Hu. 2012. Ginsenosides Rg1 and Re act as adjuvant via TLR4 signaling pathway. Vaccine 30:41064112.

Surh, Y. J., K. S. Chun, H. H. Cha, S. S. Han, Y. S. Keum, K. K. Park, and S. S. Lee. 2001. Molecular mechanisms underlying chemopreventive activities of anti-inflammatory phytochemicals: down-regulation of COX-2 and iNOS through suppression of NFkappa B activation. Mutat. Res. 480-481:243-268.

Takashima, K., N. Matsunaga, M. Yoshimatsu, K. Hazeki, T. Kaisho, M. Uekata, O. Hazeki, S. Akira, Y. Iizawa, and M. Ii. 2009. Analysis of binding site for the novel small-molecule TLR4 signal transduction inhibitor TAK-242 and its therapeutic effect on mouse sepsis model. Br. J. Pharmacol. 157:1250-1262.

Tothova, C., O. Nagy, and G. Kovac. 2014. Acute phase proteins and their use in the diagnosis of diseases in ruminants: A review. Vet. Med. (Praha) 59:163-180.

Viguier, C., S. Arora, N. Gilmartin, K. Welbeck, and R. O'Kennedy. 2009. Mastitis detection: Current trends and future perspectives. Trends Biotechnol. 27:486-493.

Wall, S., J. Gross, E. Kessler, K. Villez, and R. Bruckmaier. 2015. Blood-derived proteins in milk: Indicators of active or passive transfer. J. Dairy Sci. 98:7748-7756.
Wall, S. K., L. E. Hernandez-Castellano, A. Ahmadpour, R. M. Bruckmaier, and O. Wellnitz. 2016. Differential glucocorticoid-induced closure of the blood-milk barrier during lipopolysaccharide- and lipoteichoic acid-induced mastitis in dairy cows. J. Dairy Sci. 99:7544-7553

Wall, S. K., O. Wellnitz, R. M. Bruckmaier, and D. Schwarz. 2018. Differential somatic cell count in milk before, during, and after lipopolysaccharide- and lipoteichoic-acid-induced mastitis in dairy cows. J. Dairy Sci. 101:5362-5373.

Wellnitz, O., C. Zbinden, X. Huang, and R. Bruckmaier. 2016. Short communication: Differential loss of bovine mammary epithelial barrier integrity in response to lipopolysaccharide and lipoteichoic acid. J. Dairy Sci. 99:4851-4856.

Werner, C., A. Sobiraj, and A. Sundrum. 2010. Efficacy of homeopathic and antibiotic treatment strategies in cases of mild and moderate bovine clinical mastitis. J. Dairy Res. 77:460-467.

Yan, J. Y. 2001. Knowledge in livestock drugs. Page 17 in Handbook of Livestock Drugs, 2nd ed. The JinDun Publishing House Co. Ltd., Beijing, China.

Zaninelli, M., V. Redaelli, F. Luzi, V. Bronzo, M. Mitchell, V. Dell'Orto, V. Bontempo, D. Cattaneo, and G. Savoini. 2018. First evaluation of infrared thermography as a tool for the monitoring of udder health status in farms of dairy cows. Sensors (Basel) 18:1-12.

Zhao, B. S., Y. Liu, X. Gao, H. Zhai, J. Guo, and X. Wang. 2014. Effects of ginsenoside Rg1 on the expression of toll-like receptor 3, 4 and their signalling transduction factors in the NG108-15 murine neuroglial cell line. Molecules 19:16925-16936.

Zhao, X., and P. Lacasse. 2008. Mammary tissue damage during bovine mastitis: Causes and control. J. Anim. Sci. 86:57-65.

Zhong, K., Y. L. Wang, Y. Liu, S. X. Zou, and W. H. Chen. 2008. Establishment of experimental mastitis model by endotoxin in suining white goat and effect of astragalus polysaccharide on it. Chin. J. Vet. Sci. 28:844-847. 